\title{
Innovative Carbon Based Materials for Solid State Hydrogen Storage and Energy Storage ${ }^{\dagger}$
}

\author{
Milanese Chiara ${ }^{1}$, Alessandro Girella ${ }^{1}$, Amedeo Marini ${ }^{1}$, Daniele Pontiroli ${ }^{2}$, Mattia Gaboardi ${ }^{3}$, Giacomo \\ Magnani $^{2}$, Mauro Riccò ${ }^{2}$ \\ 1 Pavia Hydrogen Lab, Chemistry Department, University of Pavia, Italy \\ 2 Nanocarbon Laboratory, Dipartimento di Scienze Matematiche, Fisiche e Informatiche, Università Degli Studi di Parma, \\ Italy \\ 3 Elettra Sinctrotrone Trieste SCpA, Basovizza, 34012, Italy \\ * Correspondence: chiara.milanese@unipv.it; \\ $\dagger$ Presented at Materials Chemistry and Physics (Materials Chemistry 2020) - International e-Conference
}

Received: 16.09.2020; Revised: 20.09.2020; Accepted: 24.09.2020; Published: 27.09.2020

\begin{abstract}
Alkali cluster-intercalated fullerides (ACIF) consist of crystalline nanostructures in which positively charged metal clusters are ionically bond to negatively charged $\mathrm{C}_{60}$ molecules, forming charge-transfer salts. These compounds have been recently investigated with renewed interest, appearing as a novel class of materials for hydrogen storage, thanks to their proven capability to uptake reversibly high amounts of hydrogen via a complex chemisorption mechanism. In this presentation, after a short summary on the hydrogen storage topic, the synthesis, the structural investigation, and the hydrogen storage properties of $\mathrm{Li}, \mathrm{Na}$, and mixed $\mathrm{Li}-\mathrm{Na}$ clusters intercalated fullerides belonging to the families $\mathrm{Na}_{x} \operatorname{Li}_{12-\mathrm{x}} \mathrm{C}_{60}(0 \leq \mathrm{x} \leq 12)$ and $\mathrm{Na}_{\mathrm{x}} \mathrm{Li}_{6-\mathrm{x}} \mathrm{C}_{60}(0 \leq \mathrm{x} \leq 6)$ will be presented. By manometric and thermal analyses, it has been proved that $\mathrm{C} 60$ covalently binds up to $5.5 \mathrm{wt} \% \mathrm{H}_{2}$ at moderate temperature and pressure, thanks to the catalytic effect of the intercalated alkali clusters. Moreover, the destabilizing effect of $\mathrm{Na}$ in the co-intercalated $\mathrm{Na}_{x} \mathrm{Li}_{6-\mathrm{x}} \mathrm{C}_{60}$ compounds leads to an improvement of the hydrogen-sorption kinetics by about 70\%, linked to a decrease in the desorption enthalpy from 62 to 44 $\mathrm{kJ} / \mathrm{mol} \mathrm{H}_{2}$. The addition of $\mathrm{Pt}$ and $\mathrm{Pd}$ nanoparticles to Li fullerides increases up to $5.9 \mathrm{wt} \% \mathrm{H}_{2}$ the absorption performances and of about $35 \%$ the absorption rate. The ammonia storage properties of $\mathrm{Li}_{6} \mathrm{C}_{60}$ have also been investigated, resulting in quite appealing. Being the price of $\mathrm{C}_{60}$ quite high, cheaper $\mathrm{C}$ based materials are under examination. Porous biochar from agricultural waste is giving interesting results as electrode materials for high-performance supercapacitors.
\end{abstract}

Keywords: solid state hydrogen storage; C based materials; fullerene; fullerides.

(C) 2020 by the authors. This article is an open-access article distributed under the terms and conditions of the Creative Commons Attribution (CC BY) license (https://creativecommons.org/licenses/by/4.0/).

\section{Funding}

This research was funded by the Cariplo Foundation project number nr. 2013-0592, Carbonbased nanostructures for innovative $\mathrm{H}_{2}$ storage systems.

\section{Acknowledgments}

This research has no acknowledgment.

\section{Conflicts of Interest}

The authors declare no conflict of interest.

https://conferenceproceedings.international 